\title{
Equivalent Forgetting Rates in Long-term Memory for Diencephalic and Medial Temporal Lobe Amnesia
}

\author{
Richard D. McKee ${ }^{1,2}$ and Larry R. Squire ${ }^{1,3}$ \\ 'Department of Psychiatry, University of California, San Diego, La Jolla, California 92093, ${ }^{2}$ Department of Psychology, San \\ Diego State University, San Diego, California 92120, and ${ }^{3}$ Veterans Affairs Medical Center, San Diego, California 92161
}

\begin{abstract}
Amnesia can result from damage to either the midline diencephalon or the medial temporal lobe. An important related question has been whether these two forms of amnesia result in similar or different kinds of memory impairment. Earlier studies raised the possibility that differences might exist in the rate of forgetting within long-term memory, specifically, that the forgetting rate is normal in diencephalic amnesia but abnormally rapid in medial temporal lobe amnesia. In the present study, forgetting was studied in five amnesic patients with damage to the medial temporal lobe, six amnesic patients with damage to the diencephalon, and 10 normal subjects. One hundred twenty pictures were presented to the control subjects for $1 \mathrm{sec}$ each and to the amnesic patients for $8 \mathrm{sec}$ each. Retention was then tested after $10 \mathrm{~min}, 2 \mathrm{hr}$, and $30-32 \mathrm{hr}$ using four different procedures for testing recognition memory. The different exposure times for the pictures succeeded in matching the performance scores of both groups of amnesic patients and the control subjects at the $\mathbf{1 0} \mathrm{min}$ retention interval. Both groups of amnesic patients also performed similarly to control subjects at retention delays of $2 \mathrm{hr}$ and 30-32 hr. In addition, performance was nearly identical, regardless whether recognition memory was assessed by asking subjects to select the new items or the old items. The findings emphasize the similarities between medial temporal lobe and diencephalic amnesia.
\end{abstract}

Severe memory impairment can result from damage to either of two brain areas, the midline diencephalon or the medial temporal lobe. In the case of diencephalic amnesia, memory loss has been associated with bilateral damage to the dorsomedial thalamic nucleus, the anterior nucleus, the mammillothalamic tract, and the internal medullary lamina (Aggleton and Mishkin, 1983; von Cramon et al., 1985; Markowitsch, 1988). Medial temporal lobe amnesia is associated with bilateral damage to the hippocampus and adjacent anatomically related cortcx, cspecially cntorhinal, pcrirhinal, and parahippocampal cortex (Squire and Zola-Morgan, 1991).

These two regions of the brain, which when damaged cause amnesia, could make distinct contributions to memory func-

\footnotetext{
Received Jan. 16, 1992; revised Mar. 30, 1992; accepted Apr. 30, 1992.

This research was supported by the Medical Research Service of the Department of Veterans Affairs, National Institute of Mental Health Grant MH24600, the Office of Naval Research, and the McKnight Foundation. We thank Joyce Zouzounis and Teresa Doksum for research assistance.

Correspondence should be addressed to Larry R. Squire, Veterans Aftairs Medical Center, 3350 La Jolla Village Drive, San Diego, CA 92161.

Copyright (c) 1992 Society for Neuroscience $0270-6474 / 92 / 123765-08 \$ 05.00 / 0$
}

tions, or they could be part of a single functional system such that any specific contribution made by one region would be unlikely to be detected in behavioral measures. Accordingly, an important question has been whether medial temporal lobe lesions and medial diencephalic lesions produce similar or different kinds of memory impairment (for two different views, see Parkin, 1984; Victor et al., 1989). One kind of evidence, which could be taken to support the idea that there are two different kinds of amnesia, is that certain cognitive deficits occur in diencephalic amnesia that are not associated with medial temporal lobe amnesia. For example, alcoholic Korsakoff's syndrome, a well-studied example of diencephalic amnesia, can result in poor memory for temporal order (Squire, 1982; Meudell et al., 1985), deficits in metamemory (Shimamura and Squire, 1986), increased perseveration (Leng and Parkin, 1988; Janowsky et al., 1989a; Joyce and Robbins, 1991), impaired release from proactive interference (Cermak et al., 1974; Squire, 1982), and poor short-term memory (Cave and Squire, 1992). However, patients with Korsakoffs syndrome have frontal lobe atrophy in addition to their diencephalic lesions (Jacobsen and Lishman, 1987; Shimamura et al., 1988), and the aforementioned deficits can also be found in patients with circumscribed frontal lobe lesions who are not otherwise amnesic (Milner et al., 1985; Janowsky et al., 1989a,b). The question therefore remains as to whether memory impairment is similar or different following damage limited to the medial temporal lobe or the diencephalon.

Another difference between medial temporal lobe amnesia and diencephalic amnesia has been described that relates directly to the memory disturbance itself. Specifically, it has been suggested that patients with medial temporal lobe or diencephalic amnesia differ in the rate at which information is forgotten within long-term memory (for a first suggestion of this difference based on one patient; see Lhermitte and Signoret, 1972). Huppert and Piercy $(1978,1979,1982)$ assessed the forgetting rate of the severely amnesic patient H.M., who has bilateral medial temporal lobe damage, and seven patients with Korsakoff's syndrome. Subjects saw 120 pictures and were then tested by yes-no recognition after a delay of $10 \mathrm{~min}, 1 \mathrm{~d}$, and $7 \mathrm{~d}$. By varying the duration of initial exposure to the pictures (15 sec per picture for H.M., either 4 or $8 \mathrm{sec}$ for Korsakoff patients, and $1 \mathrm{sec}$ for normal subjects), similar levels of retention were obtained at the 10 min retention delay. Across the longer delays, the patients with Korsakoff's syndrome exhibited normal forgetting rates, but H.M. seemed to forget abnormally rapidly. Subsequently, normal rates of forgetting were observed for both visual and verbal material in a different group of patients with diencephalic amnesia, including patient N.A. (Squire, 
1981). Moreover, depressed patients receiving bilateral electroconvulsive therapy (ECT) exhibited rapid forgetting. If ECT is assumed to affect particularly the integrity of the medial temporal lobe, then this finding also provides support for the notion that diencephalic amnesia and medial temporal lobe amnesia differ with respect to rates of forgetting.

Two more recent studies of picture memory in patient H.M. have cast some doubt on the earlier results. $\Lambda s$ in the earlier studies, H.M. received more exposure to the pictures than did the control subjects ( $20 \mathrm{sec}$ vs $1 \mathrm{sec}$ ) in order to match his initial learning level to that of normal subjects. In the first study (Freed et al., 1987), recognition memory was assessed using both a yesno procedure and a two-alternative, forced-choice procedure. Recognition performance at the $10 \mathrm{~min}$ delay was similar for II.M. and the normal subjects. Although H.M. did perform poorly on the yes-no recognition test at a $1 \mathrm{~d}$ retention delay, he demonstrated normal retention at $3 \mathrm{~d}$ and $7 \mathrm{~d}$ retention delays. These findings indicated that medial temporal lobe damage need not produce rapid forgetting.

The second study (Freed and Corkin, 1988) indicated that H.M. could retain visual information normally for up to 6 months after learning, when the performance of H.M. and normal subjects was made equivalent at a retention delay of $10 \mathrm{~min}$. Moreover, H.M. appeared to perform better when retention was assessed by asking him to respond "yes" to a new item and "no" to a previously studied item, or when he was shown an old and a new item, side by side, and asked to select the new item. By contrast, he performed more poorly when yes-no recognition and forced-choice recognition were tested in the conventional manner by asking him to respond "yes" to an old item or to select the old item from two alternatives. These findings raised the possibility that medial temporal lobe damage might affect memory differently, depending on how memory is measured, that is, depending on whether patients are asked to identify old items or new items.

The available evidence is difficult to evaluate. First, the only data based on confirmed medial temporal lobe lesions have come from a single patient (H.M.). Second, this patient was more severely amnesic than the diencephalic amnesic patients with whom he was compared. Third, the amnesic patients did not receive the same amount of initial exposure to the learning material. Observations of normal subjects indicate that different amounts of exposure during the study phase can result in different scores on a $7 \mathrm{~d}$ retention test, even when the scores on an earlier $(10 \mathrm{~min})$ retention test are well matched (Martone et al., 1986; also see Mayes, 1988).

The present study was undertaken because of the opportunity to evaluate two groups of amnesic patients with radiologically confirmed $(n=10)$ or suspected $(n=1)$ lesions in the diencephalon or the medial temporal lobe. Because the memory impairment in the two groups was approximately similar in severity, each patient could be given the same amount of exposure to the target material $(8 \mathrm{sec})$. This amount of exposure was sufficient to produce good recognition memory performance at a short retention interval, $10 \mathrm{~min}$ after the completion of learning. Recognition memory was then compared at longer intervals, in order to assess the rate of forgetting in diencephalic and medial temporal lobe amnesia.

\section{Materials and Methods}

Eleven amnesic patients and 10 healthy control subjects viewed a series of 120 colored pictures. Then, at each of three delay intervals $(10 \mathrm{~min}$,
$2 \mathrm{hr}$, and 30-32 hr), retention was assessed using four different tests of recognition memory. The same sequence was then repeated, using new materials, approximately $14 \mathrm{~d}$ after the first test.

\section{Subjects}

Patients with damage to the hippocampal formation. Five of the patients (all male) had confirmed $(n=4)$ or suspected $(n=1)$ damage to the hippocampal formation. Four of the patients had marked reductions in the volume of the hippocampal formation bilaterally, as demonstrated by magnetic resonance imaging (MRI) (Press et al., 1989; Squire et al., 1990 , unpublished observations). The fifth patient (A.B.) was not available for MRI, but damage to the hippocampal formation is suspected based on the etiology of his impairment (anoxia). All the patients have been described previously and have participated in previous studies of memory (Cave and Squire, 1991). The patients averaged 67.8 years of age at the time of testing and had 16.0 years of education. They had an average Wechsler Adult Intelligence Scale-Revised (WAIS-R) full scale IQ of 113 , based on all the subtests. Individual IQ and Wechsler Memory Scale-Revised (WMS-R) index scores appear in Table 1. Scores for other memory tests appear in Table 2 . Note that the scores for the word recall test in Table 2 are above zero because on this test of immediate recall, several items can be retrieved from immediate memory, which is intact in amnesia. Immediate and delayed $(12 \mathrm{~min})$ recall of a short prose passage averaged 5.2 and 0 segments, respectively ( 21 segments total; Gilbert et al., 1968). The mean score on the Dementia Rating Scale (Mattis, 1976) was 131.2 (maximum possible score, 144; range, 129-134). Most of the points lost were from the memory subportion of the test (mean points lost, 8.8). The average score on the Boston Naming Test was 55.4 (maximum possible score, 60 ; range, 47-58). Scores for normal subjects on these same tests can be found elsewhere (Janowsky et al., 1989a; Squire et al., 1990).

Patients with damage to the diencephalon. Six patients had bilateral damage to midline diencephalic structures. Five of these (three men and two women) had alcoholic Korsakoff's syndrome. All five patients with Korsakoff's syndrome had participated in either an MRI study (Squire et al., 1990) or a quantitative computed tomography study (Shimamura et al., 1988), which demonstrated reductions in the volume of the mammillary nuclei, decreased tissue density within the thalamus, and frontal lobe atrophy (i.e., increased fluid volume within the frontal lobe). The sixth patient (M.G., female) became amnesic in 1986 following a bilateral thalamic infarction that was confirmed by MRI.

As a group, these six patients averaged 61.7 years of age at the time of testing and had 11.5 years of education. Their average WAIS-R full scale IQ was 100 . Individual IQ and Wechsler Memory Scale-Revised index scores appear in Table 1. Scores for other memory tests appear in Table 2. Immediate and delayed $(12 \mathrm{~min})$ recall of a short prose passage averaged 5.0 and 0 segments, respectively. The mean score on the Dementia Rating Scale (Mattis, 1976) was 131.7 (maximum score, 144; range, 125-143), with 5.8 points lost from the memory subportion of the test and 2.8 points lost from the initiation-perseveration subportion. The average score on the Boston Naming Test was 54.5 (maximum score, 60; range, 48-57).

Healthy control subjects. Ten healthy control subjects were tested (seven men and three women) who either were volunteers or employees at the Veterans Affairs Medical Center, or were recruited from the UCSD retirement community. They were selected to match the 11 amnesic patients with respect to age (mean, 63.5 years; range, 48-73), education (mean, 13.0 years; range, 7-17), and WAIS-R subtest scores for information (control subjects: mean, 21.3; amnesic patients: mean, 19.3) and vocabulary (control subjects: mean, 54.6 ; amnesic patients: mean, 53.7). Immediate and delayed $(12 \mathrm{~min})$ recall of a short prose passage averaged 7.5 and 5.5 segments, respectively.

Materials. The test was based on one originally described by Huppert and Picrcy (1976). Two complete scts of the test wcre available. Each test consisted of 240 colored slides of magazine pictures; 120 of these slides served as the study materials, and an additional 120 slides served as distractor items in four different recognition tasks. The slides depicted people, animals, scenery, and inanimate objects, as well as paintings and drawings, all of which were easily discriminable from one another. The slides were presented on Kodak 400 Audioviewers.

Procedure. In the study phase, the 120 target pictures were presented one at a time. Control subjects viewed each item for $1 \mathrm{sec}$ each. The amnesic patients viewed each picture for $4 \mathrm{sec}$ each, and then, after all 120 pictures had been presented, they viewed each picture once again 
Table 1. Characteristics of amnesic patients

\begin{tabular}{|c|c|c|c|c|c|c|c|}
\hline \multirow{2}{*}{$\begin{array}{l}\text { Lesion } \\
\text { group }\end{array}$} & \multirow{2}{*}{$\begin{array}{l}\text { Age } \\
\text { (years) }\end{array}$} & \multirow{2}{*}{$\begin{array}{l}\text { WAIS-R } \\
\text { IQ }\end{array}$} & \multicolumn{5}{|l|}{ WMS-R } \\
\hline & & & Attention & Verbal & Visual & General & Delay \\
\hline \multicolumn{8}{|c|}{ Hippocampal formation } \\
\hline A.B.* & 53 & 119 & 87 & 62 & 72 & 54 & $<50$ \\
\hline P.H. & 69 & 115 & 117 & 67 & 83 & 70 & 57 \\
\hline W.H. & 69 & 113 & 88 & 72 & 82 & 67 & $<50$ \\
\hline W.I. & 77 & 104 & 92 & 72 & 82 & 71 & 58 \\
\hline J.L. & 71 & 116 & 122 & 73 & 83 & 74 & 58 \\
\hline Mean & 67.8 & 113.4 & 101.2 & 69.2 & 80.4 & 67.2 & 57.7 \\
\hline \multicolumn{8}{|c|}{ Diencephalon } \\
\hline N.C. & 48 & 90 & 62 & 80 & 60 & 69 & $<50$ \\
\hline R.C. & 74 & 106 & 115 & 76 & 97 & 80 & 72 \\
\hline V.F. & 71 & 103 & 101 & 78 & 72 & 72 & 66 \\
\hline M.G. & 59 & 111 & 113 & 89 & 84 & 86 & 63 \\
\hline P.N. & 63 & 94 & 81 & 77 & 73 & 67 & 53 \\
\hline J.W. & 55 & 98 & 87 & 65 & 70 & 57 & 57 \\
\hline Mean & 61.7 & 100.3 & 96 & 77.5 & 76.0 & 71.8 & 62.2 \\
\hline
\end{tabular}

WAIS-R IQ, Wechsler Adult Intelligence Scale-Revised Full Scale IQ; WMS-R, Wechsler Memory Scale-Revised. The W $\Lambda$ IS-R and each of the five indices of the WMS-R yield a mean score of 100 in the normal population, with a standard deviation of 15 . The WMS-R does not provide scores for subjects who score below 50 . Therefore, the three scores below 50 were scored as 50 for calculating group means.

* Although the site of lesion was not confirmed radiologically, the ctiology of the amnesia (anoxia) suggests that damage has occurred to the hippocampal formation.

for $4 \mathrm{sec}$ each. Thus, each picture was exposed to the amnesic patients for a total of $8 \mathrm{sec}$ and to the control subjects for a total of $1 \mathrm{sec}$. All subjects were instructed to study the pictures so that they might recognize them if they were presented at a later time.

Ten minutes, $2 \mathrm{hr}$, and $30-32 \mathrm{hr}$ after completing the study session, all of the subjects were tested for retention using four different recognition memory tests. There were two yes-no recognition tests and two forced-choice recognition tests. The first test required subjects to respond "yes" to a previously studied (old) item and "no" to a new item that had not been presented previously (yes-no, old). The second test required subjects to respond "yes" to a new item and "no" to an old item (yes-no, new). In the third test, subjects viewed two items side by side on two different screens, one old and one new, and were asked to point to the old item (delayed match to sample, or DMS). In the fourth

Table 2. Performance on standard memory tests

\begin{tabular}{|c|c|c|c|c|c|c|c|c|}
\hline \multirow{2}{*}{$\frac{\text { Lesion group }}{\text { Hippocampal }}$} & $\begin{array}{l}\text { Diagram } \\
\text { recall }\end{array}$ & \multicolumn{3}{|c|}{ Paired associates } & $\begin{array}{l}\text { Word } \\
\text { recall } \\
(\%)\end{array}$ & \multirow[t]{2}{*}{$\begin{array}{l}\text { Word } \\
\text { recog- } \\
\text { nition } \\
(\%)\end{array}$} & \multirow[t]{2}{*}{$\begin{array}{l}50 \\
\text { words }\end{array}$} & \multirow[t]{2}{*}{$\begin{array}{l}50 \\
\text { faces }\end{array}$} \\
\hline & & & & & & & & \\
\hline A.B. & 4 & 1 & 1 & 2 & 33 & 83 & 32 & 33 \\
\hline P.H. & 3 & 0 & 0 & 1 & 27 & 84 & 36 & 34 \\
\hline W.H. & 1 & 0 & 0 & 0 & 40 & 84 & 29 & 24 \\
\hline W.I. & 0 & 0 & 0 & 0 & 29 & 85 & 31 & 30 \\
\hline J.L. & 1 & 0 & 0 & 0 & 40 & 93 & 31 & 20 \\
\hline Mean & 1.8 & 0.2 & 0.2 & 0.6 & 33.8 & 85.8 & 31.8 & 28.2 \\
\hline \multicolumn{9}{|l|}{ Diencephalon } \\
\hline N.C. & 0 & 1 & 0 & 1 & 23 & 71 & 31 & 37 \\
\hline R.C. & 3 & 0 & 0 & 3 & 19 & 85 & 37 & 30 \\
\hline V.F. & 8 & 0 & 0 & 0 & 27 & 90 & 27 & 31 \\
\hline M.G. & 0 & 0 & 0 & 2 & 33 & 71 & 30 & 34 \\
\hline P.N. & 2 & 1 & 1 & 1 & 29 & 83 & 27 & 38 \\
\hline J.W. & 4 & 0 & 0 & 2 & 29 & 90 & 29 & 34 \\
\hline Mean & 2.8 & 0.3 & 0.2 & 1.5 & 26.7 & 81.7 & 30.2 & 34.0 \\
\hline $\begin{array}{l}\text { Controls (mea } \\
\quad N=8)\end{array}$ & 20.6 & 6.0 & 7.6 & 8.9 & 71.3 & 97.6 & 41.1 & 38.1 \\
\hline
\end{tabular}

Diagram recall score is based on delayed (12 min) reproduction of the Rey-Osterreith figure (Osterreith, 1944; maximum score, 36), and average score for copying the figure was 27.3, a normal score (Kritchevsky et al., 1988); paired-associate scorcs arc the number of word pairs recalled on three successive trials (maximum score, 10/trial); word recall is the percentage of words identified correctly across five successive study-test trials (Rey, 1964); word recognition score is the percentage of words identified correctly by a yes-no recognition test across five successive study-test trials; score for words and faces is based on a $24 \mathrm{hr}$ recognition test of 50 words or 50 faces (modified from Warrington, 1984; maximum score, 50; chance, 25). The mean scores for normal control subjects on these tests are from Squire and Shimamura (1986). 
Figure 1. Memory for visual material at three retention delays, as measured by four recognition memory tests (yesno recognition, yes $=$ old, no $=$ new; two-alternative forced-choice DMS; yes - no recognition, yes $=$ new, no $=$ old; two-alternative forced-choice DNMS). Scores represent the average percentage correct for healthy control subjects (open circles; $n=10$ ), amnesic patients with damage to the hippocampal formation (solid triangles; $n=5$ ), and amnesic patients with damage to the diencephalon (solid squares; $n=6$ ). At study, the control subjects viewed 120 items for $1 \mathrm{sec}$ each, while the amnesic patients viewed each item for a total of $8 \mathrm{sec}$. Across the 12 data points (4 tests $\times 3$ delay intervals), standard errors averaged $3.2 \%$ (range, $2.2-5.9 \%$ ) for the control subjects, $5.8 \%$ (range, $3.6-9.9 \%$ ) for the patients with damage to the hippocampal formation, and $3.6 \%$ (range, 1.7-7.5\%) for the patients with damage to the diencephalon.
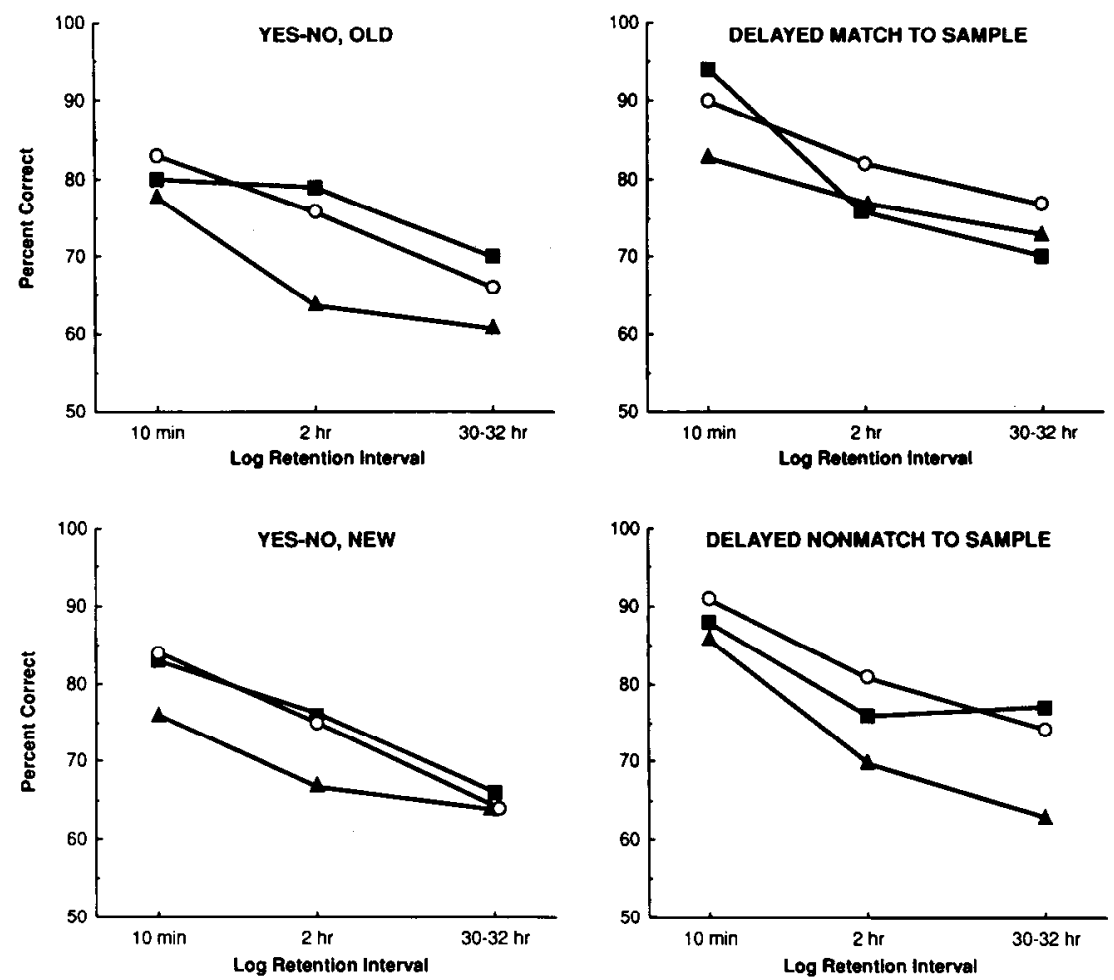

test, subjects viewed an old and a new item side by side on two different screcns and wcre asked to point to the new item (delayed nonmatch to sample, or DNMS).

A total of 40 unique target items and 40 unique distractor items were presented at each of the three delay intervals. At each delay interval, 10 of the 40 target items and 10 of the 40 distractor items were used for each of the four types of recognition test, and testing was completed with one kind of recognition test before moving to a different test. Within each subject group, the four recognition tests at each retention interval were ordered such that each type of recognition test was equally likely to appear in each serial position. Target and distractor items were randomly intermixed within each type of recognition test with the constraint that no more than three items of any one type occurred consecutively. Within each subject group, each target item and each distractor item were equally likely to appear at each delay interval and in each recognition test. All subjects were tested twice, using the two different forms of the test. The two forms were always administered in the same order. A minimum interval of $5 \mathrm{~d}$ was scheduled between the final test session using the first form and the study session using the second form (average interval, $14 \mathrm{~d}$ ).

\section{Results}

Figure 1 shows performance across three delay intervals for the three subject groups and the four recognition memory tasks. Because the scores obtained with the two different forms of the test materials were very similar (average overall difference $=$ $2.5 \%$ ), data obtained from the two forms were combined prior to carrying out statistical analyses. Scores were calculated as the total percentage of correct responses. It is important to note that performance at the 10 min delays was similar across the three groups, which suggests that the extra study time provided to the amnesic patients was successful in raising their performance for the 10 min delay to approximately normal levels. Average 10 min test scores for the control subjects, patients with hippocampal damage, and patients with diencephalic damage, respectively, were $83 \pm 3.1 \%( \pm \mathrm{SEM}), 78 \pm 4.5 \%$, and $80 \pm 2.3 \%$ for the yes-no, old test; $84 \pm 3.2 \%, 76 \pm 4.7 \%$, and $83 \pm 3.2 \%$ for the yes-no, new test; $90 \pm 3.5 \%, 83 \pm 5.6 \%$, and $94 \pm 2.4 \%$ for the DMS test; and $91 \pm 2.3 \%, 86 \pm 4.0 \%$, and $88 \pm 1.7 \%$ for the DNMS test. Given that the groups performed similarly at the $10 \mathrm{~min}$ delay interval, the important finding was that scores were also similar across groups at the two longer delay intervals.

Statistical analysis confirmed these impressions. A three-way repeated-measures ANOVA ( 3 groups $\times 4$ tests $\times 3$ delays) showed no effect of group $(F[2,18]=1.33, p>0.10)$ and no interactions ( $p$ values $>0.10$ ). There were significant effects of delay interval $(F[2,36]=71.7, p<0.001)$ and type of recognition memory test $(F[3,54]=14.0, p<0.001)$. The effect of test type reflects the typical finding that scores are higher overall on forcedchoice recognition tests than on yes-no recognition tests. By contrast, there was no evidence that amnesia affected memory differently depending on whether patients were asked to identify old items (i.e., on the yes-no, old and DMS tests) versus new items (i.e., on the yes-no, new and DNMS tests; controls, 79\% vs $78 \%$; patients with hippocampal damage, $72 \%$ vs $71 \%$; patients with diencephalic damage, $78 \%$ vs $77 \%$; the largest difference at any delay interval was $67 \%$ vs $63 \%$ for the patients with hippocampal damage at the 30-32 hr delay).

Post hoc $t$ tests provided additional evidence that control subjects, patients with hippocampal damage, and patients with diencephalic damage performed similarly at all three test intervals, regardless of test type. Among 36 possible comparisons ( 3 delay intervals $\times 4$ tests $\times 3$ pairwise comparisons at each delay interval), the only significant differences between groups occurred at the $2 \mathrm{hr}$ delay on the yes-no, old test (patients with hippocampal damage vs control subjects: $64 \%$ and $76 \%$ respectively, $t[13]=2.59, p<0.05$; patients with hippocampal damage vs patients with diencephalic damage: $64 \%$ and $79 \%$ respectively, $t[9]=3.04, p<0.05$ ). At the 30-32 hr delay interval, the scores of the three groups were similar on all four tests. The largest difference between groups at this delay occurred for the hippocampal and diencephalic patients on the 


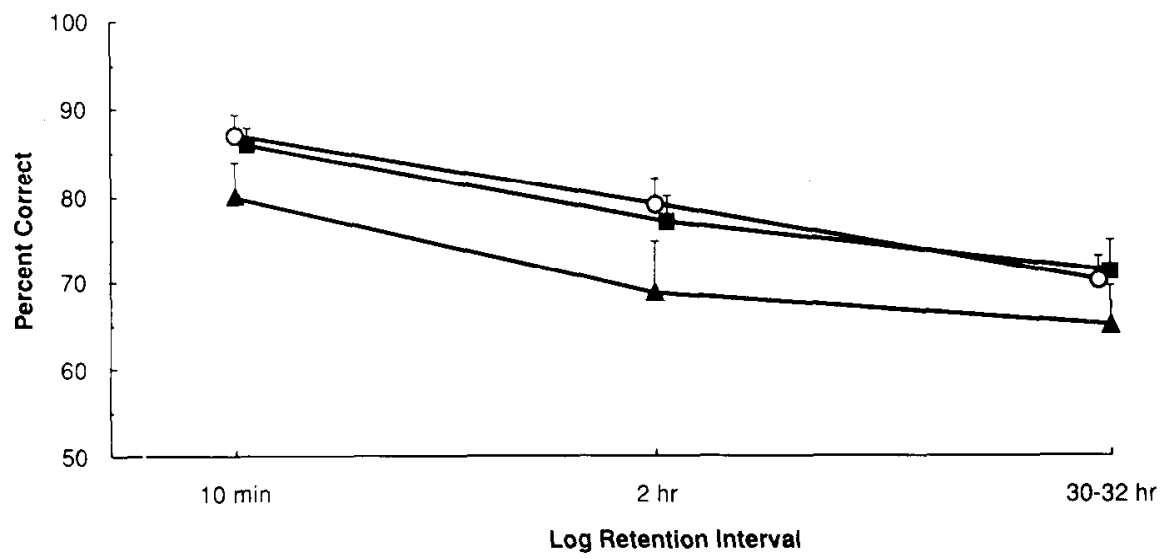

Figure 2. Memory for visual material at three retention delays, averaged across four different recognition memory tests. Scores indicate the average percent correct for healthy control subjects (open circles; $n=10$ ), amnesic patients with damage to the hippocampal formation (solid iriangles; $n=5$ ), and amnesic patients with damage to the diencephalon (solid squares; $n=6$ ). Error bars show SEM.

DNMS test (hippocampal patients, 63\%; diencephalic patients, $79 \% ; t[9]=1.61, p>0.10$ ).

Figure 2 shows the performance of the three groups combined across all four tests, and Table 3 shows the scores of the individual patients, also combined across the four tests. A comparison of the two patient groups in a separate analysis of variance ( 2 groups $\times 3$ delays) revealed the anticipated effect of delay interval $(F[2,18]=37.6, p<0.001)$ but no effect of group $(F[1,9]=1.56, p>0.10)$ and no interaction $(F<1)$.

Although the difference between the two patient groups was not statistically significant, Figure 2 indicates that the average scores of the patients with hippocampal formation damage were numerically lower at all three delay intervals than the scores of the patients with damage to the diencephalon. An examination of the scores of individual patients (Table 3 ) revealed that this numerical difference was largely due to patient W.I. in the group with hippocampal formation damage, who scored especially poorly at all three delays. Patient W.I. apparently acquired less information during the study session than the other patients, as indicated by his overall performance of only $66.3 \%$ at the 10

Table 3. Individual percentage correct scores of amnesic patients

\begin{tabular}{llll} 
& \multicolumn{2}{l}{ Delay } & \\
\cline { 4 - 4 } Lesion group & $10 \mathrm{~min}$ & $2 \mathrm{hr}$ & $\begin{array}{l}30-32 \\
\mathrm{hr}\end{array}$ \\
\hline Hippocampal formation & & & \\
A.B. & 81.8 & 68.8 & 63.1 \\
P.H. & 82.5 & 65.9 & 66.9 \\
W.H. & 81.9 & 75.0 & 65.6 \\
W.I. & 66.3 & 51.0 & 51.3 \\
J.L. & 90.0 & 85.6 & 78.8 \\
Mean & 80.5 & 69.3 & 65.1 \\
Mean without W.I. & 84.1 & 73.8 & 68.6 \\
Diencephalon & & & \\
N.C. & 81.3 & 65.6 & 71.9 \\
R.C. & 90.0 & 76.3 & 73.1 \\
V.F. & 81.3 & 76.9 & 58.8 \\
M.G. & 90.6 & 86.6 & 82.5 \\
P.N. & 86.3 & 72.5 & 61.3 \\
J.W. & 86.9 & 81.3 & 76.3 \\
$\quad$ Mean & 86.0 & 76.5 & 70.6 \\
Controls (mean, $N=10)$ & 87.0 & 78.6 & 70.1 \\
\hline
\end{tabular}

Numbers are percentage correct scores averaged across the four recognition memory tests. min delay. W.I. was the oldest amnesic patient tested, and recent assessments suggest that his cognitive abilities have begun to decline. If patient W.I. is excluded, the average scores of the two patient groups are even more similar (Table 3). After performing virtually the same at the 10 min delay interval (difference of $1.9 \%$ ), the two patient groups also performed very similarly at the $2 \mathrm{hr}$ delay (difference $=2.7 \%$ ) and at the $30-32 \mathrm{hr}$ delay (difference $=2.0 \%$ ). In addition, the scores on the DNMS test (Fig. 1, bottom right) become more similar when patient W.I. is excluded. Specifically, without patient W.I. the scores at the 30-32 hr delay become $69 \%$ for patients with hippocampal formation damage and $77 \%$ for patients with diencephalic damage $(t[8]=1.04, p>0.10)$. Overall, there was no hint of more rapid forgetling in the group with hippocampal damage.

A power analysis (Cohen, 1969) indicated that there was a probability of $80 \%$ (i.e., power $=80 \%$ ) of detecting a moderate difference in the rate of forgetting between the two patient groups, that is, a moderate group $\times$ delay interaction. Specifically, given the observed $5.6 \%$ difference between the two patient groups at the 10 min delay (Fig. 2), there was an $80 \%$ probability of detecting a total difference of $16.3 \%$ at the two longer delays (e.g., a $5.3 \%$ difference at the 2 hr delay and an $11 \%$ difference at the 30-32 hr delay). Another way to express the findings from the power analysis is that, if the scores for the two groups had been identical at the $10 \mathrm{~min}$ delay, then a total difference of 0.65 standard deviations could have been detected between average scores for the two groups at the two longer delays. This substantial ability to reveal a group $\times$ delay interaction, despite the small number of patients in each group, resulted from the fact that each subject was tested at all three delay intervals with all four different recognition tests.

Table 4. Discriminability $\left(d^{\prime}\right)$ scores averaged across four recognition tests

\begin{tabular}{llll} 
& \multicolumn{2}{l}{ Delay } & \\
\cline { 2 - 4 } Group & $10 \mathrm{~min}$ & $2 \mathrm{hr}$ & $\begin{array}{l}30-32 \\
\mathrm{hr}\end{array}$ \\
\hline Control & 2.39 & 1.63 & 1.04 \\
Hippocampal formation & 1.72 & 1.04 & 0.78 \\
Diencephalon & 2.17 & 1.54 & 1.07
\end{tabular}

Numbers are average $d^{\prime}$ scores for each group across the four recognition memory tests. This score provides an unbiased estimate of recognition memory that is not influenced by a subject's decision criterion. 
When the data were evaluated with signal detection analysis, using unbiased measures of discriminability $\left(d^{\prime}\right)$ and bias $(\beta)$ (Green and Swets, 1966), the results were similar to those just described. Table 4 shows the overall performance of each patient group at the three delay intervals, expressed as average $d^{\prime}$ scores across the four recognition tests. For each subject, values of $d^{\prime}$ for the two yes-no tests were computed at each delay interval and for each test, based on the proportion of hits (correct "yes" responses) and false alarms (incorrect "yes" responses) (see Swets, 1964, Table I, Appendix I). The $d^{\prime}$ scores for the two forcedchoice tests were also computed (Swets, 1964, Table II, Appendix I). When the proportion of hits or false alarms for an individual subject was 0 or $1.0,0$ was replaced by $1 /(2 N)$ and 1.0 was replaced by $1-1 /(2 N)$, where $N$ is the number of trials in which a particular item was presented (Bock and Jones, 1968). A three-way repeated-measures ANOVA ( 3 groups $\times 4$ tests $\times$ 3 delays) revealed no effect of group $(F[2,18]=1.36, p>0.10)$ or test type $(F[3,54]=1.0, p>0.10)$, and no interactions (all $F$ values $<1.35$ ). Again, the effect of delay interval was significant $(F[2,36]=68.7, p<0.001)$. Just as with the analysis based on percentage correct scores, the only differences in $d^{\prime}$ scores occurred at the $2 \mathrm{hr}$ delay interval for the yes-no, old test. At the 30-32 hr delay, the largest difference in $d^{\prime}$ scores was between the patients with diencephalic damage and the patients with hippocampal formation damage on the yes-no, new test (1.98 vs $0.98 ; t[9]=1.97, p=0.10)$.

The decision criterion $(\beta)$ for a subject in a yes-no recognition test is influenced by the relative frequency of target items and distractors, and also by the value that subjects assign to correct and incorrect responses. Subjects in the three groups used the same criterion $(\beta)$ to make judgments for the two yes-no recognition tests (means for the three groups range from 1.73 to 2.75). $\beta$ values are negligible for two-alternative, forced-choice tests (Green and Swets, 1966).

\section{Discussion}

Forgetting of newly learned visual information within long-term memory (i.e., up to 30-32 hr after learning) occurred at an equivalent rate for patients with diencephalic amnesia and patients with medial temporal lohe amnesia. This is the first study of forgetting rates in a group of amnesic patients with medial temporal lobe damage, whose severity of amnesia, amount of initial learning, and retention test delays were the same as in a comparison group of diencephalic amnesic patients (see Mayes, 1988 , for a discussion of the importance of these factors). Our findings for diencephalic amnesia were consistent with a substantial body of evidence showing normal forgetting rates in this group (Huppert and Piercy, 1978; Squire, 1981; Butters et al., 1988; Kopelman, 1985). Our findings for medial temporal lobe amnesia differ from the first reports of forgetting rates based on patient H.M. (Huppert and Piercy, 1978, 1979) but are in agreement with later work suggesting that H.M.'s forgetting rate within long-term memory is normal (Freed et al., 1987; Freed and Corkin, 1988). The present findings are also consistent with reports that forgetting occurs at a normal rate in Alzheimer's disease, a disorder in which prominent neuropathology occurs in the medial temporal lobe (Kopelman, 1985; Freed et al., 1989).

A second finding of the present study was that retention scores were nearly identical regardless whether subjects were asked to identify old items (yes-no, old and DMS) or new items (yesno, new and DNMS). Thus, the present findings do not bear out the suggestion, based on a single-case study with patient H.M., that amnesic performance might be better on recognition memory tasks that permit subjects to express a "preference for novelty," (i.e., by responding "yes" to a new item or by choosing the new item from a pair of items) (Freed and Corkin, 1988). Indeed, the largest difference between the scores in the two kinds of tests (67\% vs $63 \%$; patients with hippocampal damage at the 30-32 hr retention delay) was in the opposite direction from what one would have expected based on the earlier study.

The idea that forgetting rate might provide a signature of medial temporal lobe and diencephalic amnesia has been widely discussed during the past 10 years (Huppert and Piercy, 1982; Parkin, 1984; Squire and Cohen, 1984; Mayes, 1988), despite the fact that the principal evidence for this idea came from studies of a single patient (Huppert and Piercy, 1978, 1979). Moreover, early discussions of the original work did point out that this patient (H.M.) was not always well matched to normal subjects at short delays and that his forgetting rate was not strikingly different from normal (Deutsch, 1984; Weiskrantz, 1985). Recently, the possibility that forgetting rates differ among types of amnesia was raised again based on a different method (Butters et al., 1988). In this study, patients with Korsakoff's syndrome and patients with presumed medial temporal lobe damage were compared in terms of index scores on the WMS$\mathrm{R}$ (Wechsler, 1987). The finding was that the patients with medial temporal lobe damage had a larger difference between the General Memory Index and the Delayed Index (77.0 vs 56.6) than did the patients with Korsakoff's syndrome (65.4 vs 56.6). Although these scores might suggest a difference in forgetting rates in the two groups, the two groups cannot be directly compared because the two scores against which forgetting is evaluated (77.0 and 65.4) lie at different points on the measurement scale. Because one cannot assume that the scale is linear, it is difficult to compare a numerical difference that arises at one part of the scale with a difference that arises at another part of the scale (Krantz and Tversky, 1971; Loftus, 1978, 1985; Bogartz, 1990; Wixted, 1990).

In another study that used a different method, the patients with medial temporal lobe damage were reported to have more rapid forgetting than patients with diencephalic damage (Parkin and Leng, 1988). However, in this case the group with medial temporal lobe damage was known to have more severe memory impairment than the other group, and the groups were not well matched with respect to initial learning.

There have also been reports of abnormally rapid forgetting in memory-impaired patients, for example, in depressed patients with amnesia shortly after prescribed ECT (Squire, 1981) and in head-injured patients with posttraumatic amnesia (Levin et al., 1987). However, in these cases, the anatomical basis of the amnesia has not been established. Finally, a preliminary report had suggested that monkeys with large medial temporal lobe lesions might forget more rapidly than monkeys with diencephalic lesions (Zola-Morgan and Squire, 1982). However, this finding was obtained in two groups that differed in severity of memory impairment. Subsequent observations involving monkeys with more restricted medial temporal lobe lesions, whose memory impairment was equivalent in severity to that of monkeys with diencephalic lesions, suggest that the two groups exhibit similar fates of forgetting (S. Zola-Morgan and L. R. Squire, unpublished observations; see also Mayes, 1988, for a discussion of other animal research on this topic).

It is worth emphasizing that the finding of normal forgetting 
rates in amnesia is entirely compatible with the well-known observation that in amnesia, information is rapidly forgotten as one moves from short-term memory to long-term memory. In this sense, it is accurate to describe all amnesias as syndromes of rapid forgetting. Information is intact in short-term memory and then not available in long-term memory. The present experiment concerned the more specific question as to whether the rate of forgetting within long-term memory is normal or abnormal and whether it is similar or different in the two kinds of amnesia. In the present study, the comparison of forgetting rates between patient groups was possible because the two amnesic groups exhibited the same level of initial learning. The findings indicate that forgetting within long-term memory occurs at an equivalent and apparently normal rate in both medial temporal lobe and diencephalic amnesia. The impairment in anterograde amnesia may be related mainly to the amount of information that enters long-term memory, rather than to the rate of decay within long-term memory. Previous studies of normal subjects also suggested that rate of forgetting tends to be a stable property of long-term memory that is unaffected by variations in the level of original learning (Slamecka and McElree, 1983).

Apart from forgetting rate, Parkin (1984) has proposed other markers for distinguishing medial temporal lobe and diencephalic amnesia. However, in making comparisons between amnesic groups, insufficient attention has been paid to the possibility that quantitative differences in the severity of memory impairment can account for differences in performance (e.g., see Mattis et al., 1978; for additional discussion, see Weiskrantz, 1985). In addition, most of the ideas that have been proposed for distinguishing the two kinds of amnesia are based on studies of patients with alcoholic Korsakoff's syndrome. As discussed here and elsewhere (Schacter, 1987; Shimamura et al., 1991), many of the differences between diencephalic and media temporal lobe amnesia are a result of frontal lobe pathology, which typically occurs in Korsakoff's syndrome, the most commonly studied examples of diencephalic amnesia. More studies are needed of patients with diencephalic amnesia other than those with alcoholic Korsakoff's syndrome (cf. Graff-Radford et al., 1990).

Finally, patterns of retrograde amnesia have sometimes been considered to be characteristically different in medial temporal lobe and diencephalic amnesia (Parkin, 1984; Squire and Cohen, 1984). However, the reported differences can probably be attributed to the difficulty of obtaining a direct measure of retrograde amnesic in alcoholic Korsakoff patients that is not confounded with anterograde amnesia. More recent evidence suggests that the patterns of retrograde memory impairment in the two kinds of amnesia are quite similar (Squire et al., 1989). Currently, there is no compelling basis for separating medial temporal lobe and diencephalic amnesia based on patterns of retrograde amnesia.

In summary, although the neuropathology associated with medial temporal lobe and diencephalic amnesia can be readily differentiated, even in living patients (Squire et al., 1990), it has not been established that the two kinds of amnesia result in distinct patterns of memory loss. Certainly, it is reasonable to suppose that the medial temporal lobe and the diencephalic midline should make different contributions to normal memory. However, each region may also be an essential component in a larger functional system, such that a similar amnesia results from damage to any portion of that system. There are many similarities between medial temporal lobe amnesia and diencephalic amnesia. The question of whether or not there are also differences in the pattern of memory impairment remains an important topic for study.

\section{References}

Aggleton JP, Mishkin M (1983) Visual recognition impairment following medial thalamic lesions in monkeys. Neuropsychologia 21: $183-197$.

Bock RD, Jones LV (1968) The measurement and prediction of judgment and choice. San Francisco: Holden-Day.

Bogartz RS (1990) Evaluating forgetting curves psychologically. J Exp Psychol [Hum Learn] 16:138-148.

Butters N, Salmon DP, Cullum CM, Cairns P, Troster AI, Jacobs D (1988) Differentiation of amnesic and demented patients with the Wechsler Memory Scale-Revised. Clin Neuropsychol 2:133-148.

Cave CB, Squire LR (1991) Equivalent impairment of spatial and nonspatial memory following damage to the human hippocampus. Hippocampus 1:329-340.

Cave CB, Squire LR (1992) Intact verbal and spatial short-term memory following damage to the human hippocampus. Hippocampus 2 : 151-164.

Cermak LS, Butters N, Moreines J (1974) Some analyses of the verbal encoding deficit of alcoholic Korsakoff patients. Brain Lang 1:141150.

Cohen J (1969) Statistical power analysis for the behavioral sciences. New York: Academic.

Deutsch JA (1984) Amnesia and a theory for dating memories. In: Neurobiology of learning and memory (Lynch G, McGaugh JL, Weinberger NM, eds). New York: Guilford.

Freed DM, Corkin S (1988) Rate of forgetting in H.M.: 6-month recognition. Behav Neurosci 102:823-827.

Freed DM, Corkin S, Cohen NJ (1987) Forgetting in H.M.: a second look. Neuropsychologia 25:461-471.

Freed DM, Corkin S, Growden JH, Nissen MJ (1989) Selective attention in Alzheimer's disease: characterizing cognitive suhgroups of patients. Neuropsychologia 27:325-339.

Gilbert J, Levee R, Catalano K (1968) A preliminary report on a new memory scale. Percept Mot Skills 27:277-278.

Graff-Radford NR, Tranel D, Van Hoesen GW, Brandt J (1990) Diencephalic amnesia. Brain 113:1-25.

Green DM, Swets JA (1966) Signal detection theory and psychophysics. New York: Wiley.

Huppert FA, Piercy M (1976) Recognition memory in amnesic patients: effect of temporal context and familiarity of material. Cortex $12: 3-20$.

Huppert FA, Piercy M (1978) Dissociation between learning and remembering in organic amnesia. Nature 275:317-318.

Huppert FA, Piercy M (1979) Normal and abnormal forgetting in organic amnesia: effect of locus of lesion. Cortex 15:385-390.

Huppert FA, Piercy M (1982) In search of the functional locus of amnesic syndromes. In: Human memory and amnesia (Cermak LS, ed). Hillsdale, NJ: Erlbaum.

Jacobsen RR, Lishman WA (1987) Selective memory loss and global intellectual deficits in alcoholic Korsakoff's syndrome. Psychol Med 17:649-655.

Janowsky JS, Shimamura AP, Kritchevsky M, Squire LR (1989a) Cognitive impairment following frontal lobe damage and its relevance to human amnesia. Behav Neurosci 103:548-560.

Janowsky JS, Shimamura AP, Squire LR (1989b) Source memory impairment in patients with frontal lobe lesions. Neuropsychologia 27:1043-1056.

Joyce EM, Robbins TW (1991) Frontal lobe function in Korsakoff and non-Korsakoff alcoholics: planning and spatial working memory. Neuropsychologia 29:709-723.

Kopelman MD (1985) Rate of forgetting in dementia of the Alzheimer's type and Korsakoff's syndrome. Neuropsychologia 23:623-638.

Krantz DH, Tversky A (1971) Conjoint-measurement analysis of composition rules in psychology. Psychol Rev 78:151-169.

Kritchevsky M, Squire LR, Zouzounis JA (1988) Transient global amnesia: characterization of anterograde and retrograde amnesia. Neurology 38:213-219.

Leng NRC, Parkin AJ (1988) Double dissociation of dysfunction in organic amnesia. Br J Clin Psychol 27:359-362. 
Levin HS, High WM, Eisenberg H (1987) Learning and forgetting during and after post-traumatic amnesia in head injured patients. Soc Neurosci Abstr 13:205.

Lhermitte F, Signoret J-L (1972) Analyse neuropsychologique et differenciation des syndromes amnesiques. [Neuropsychological analysis and differentiation of amnesic syndromes.] Rev Neurol (Paris) 126:161-178.

Loftus GR (1978) On interpretation of interactions. Mem Cogn 6: 312-319.

Loftus GR (1985) Evaluating forgetting curves. J Exp Psychol [Hum Learn] 11:397-406.

Markowitsch HJ (1988) Diencephalic amnesia: a reorientation towards tracts? Brain Res Rev 13:351-370.

Martone M, Butters N, Trauner D (1986) Some analyses of forgetting of pictorial material in amnesic and demented patients. J Clin Exp Neuropsychol 8:161-178.

Mattis S (1976) Dementia rating scale. In: Geriatric psychiatry (Bellack R, Keraso B, eds). New York: Grune and Stratton.

Mattis S, Kovner R, Goldmeier E (1978) Different patterns of mnemonic deficits in two organic amnesic syndromes. Brain Lang 6:179191.

Mayes AR (1988) Human organic memory disorders. New York: Cambridge UP.

Meudell PR, Mayes AR, Ostergaard A, Pickering A (1985) Recency and frequency judgments in alcoholic amnesics and normal people with poor memory. Cortex 21:487-511.

Milner B, Petrides M, Smith ML (1985) Frontal lobes and the temporal organization of memory. Hum Neurobiol 4:137-142.

Osterreith P (1944) Le test de copie d'une figure complexe. [The test of copying a complex figure.] Arch Psycol (Paris) 30:206-356.

Parkin AJ (1984) Amnesic syndrome: a lesion-specific disorder? Cortex 20:479-508.

Parkin AJ, Leng NRC (1988) Comparative studies of human amnesia: syndrome of syndromes? In: Information processing by the brain (Markowitsch HJ, ed). Toronto: Hans Huber.

Press GA, Amaral DG, Squire LR (1989) Hippocampal abnormalities in amnesic patients revealed by high-resolution magnetic resonance imaging. Nature 341:54-57.

Rey A (1964) L'examen clinique en psychologie. [The clinical exam in psychology.] Pams: Universitaires de France.

Schacter DL (1987) Memory, amnesia, and frontal lobe dysfunction. Psychobiology 15:21-36.

Shimamura AP, Squire LR (1986) Memory and metamemory: a study of the feeling of knowing phenomenon in amnesic patients. J Exp Psychol [Hum Learn] 12:452-460.

Shimamura AP, Jernigan TL, Squire LR (1988) Korsakoff's syndrome: radiological (CT) findings and neuropsychological correlates. J Neurosci 8:4400-4410.

Shimamura AP, Janowsky JS, Squire LR (1991) What is the role of frontal lobe damage in memory disorders? In: Frontal lobe function and dysfunction (Levin HD, Eisenberg HM, Benton AL, eds). New York: Oxford UP.

Slamecka NJ, McElree B (1983) Normal forgetting of verbal lists as a function of their degree of learning. J Exp Psychol [Hum Learn] 9: 384-397.

Squire LR (1981) Two forms of human amnesia: an analysis of forgetting. J Neurosci 1:635-640.

Squire LR (1982) Comparisons between forms of amnesia: some deficits are unique to Korsakoff's syndrome. J Exp Psychol [Hum Learn] 8:560-571.

Squire LR, Cohen NJ (1984) Human memory and amnesia. In: Neurobiology of learning and memory (Lynch G, McGaugh JL, Weinberger NM, eds). New York: Guilford.

Squire LR, Shimamura AP (1986) Characterizing amnesic patients for neurobehavioral study. Behav Neurosci 100:866-877.

Squire LR, Zola-Morgan S (1991) The medial temporal lobe memory system. Science 253:1380-1386.

Squire LR, Haist F, Shimamura AP (1989) The neurology of memory: quantitative assessment of retrograde amnesia in two groups of amnesic patients. J Neurosci 9:828-839.

Squire LR, Amaral DG, Press GA (1990) Magnetic resonance measurements of hippocampal formation and mammillary nuclei distinguish medial temporal lobe and diencephalic amnesia. J Neurosci 10 : 3106-3117.

Swets JA, ed (1964) Signal detection and recognition by human observers: contemporary readings. New York: Wiley.

Victor M, Adams RD, Collins GH (1989) The Wernicke-Korsakoff syndrome, $2 \mathrm{~d}$ ed. Philadelphia: Davis.

von Cramon DY, Hebel N, Schuri U (1985) A contribution to the anatomical basis of thalamic amnesia. Brain 108:993-1008.

Warrington EK (1984) Recognition memory test. Windsor, Ontario: NFER-Nelson.

Wechsler D (1987) Wechsler Memory Scale-Revised. New York: Psychological Corporation.

Weiskrantz L (1985) On issues and theories of the human amnesic syndrome. In: Memory systems of the brain (Weinberger NM, McGaugh JL, Lynch G, eds). New York: Guilford.

Wixted JT (1990) Analyzing the empirical course of forgetting. J Exp Psychol [Hum Learn] 16:927-935.

Zola-Morgan S, Squire LR (1982) Two forms of amnesia in monkeys: rapid forgetting after medial temporal lobe lesions but not diencephalic lesions. Soc Neurosci Abstr 8:24. 